\title{
Geological- and Chemical-Based Environmental Risk Factor Sustainability Model
}

\author{
By Daniel T. Rogers ${ }^{1}$
}

\begin{abstract}
:
An environmental sustainability model that integrates natural and anthropogenic factors was developed and tested for 10 years. The model is composed of calculated geological risk factors, chemical risk factors, and operational aspects of environmental regulatory requirements which are integrated into a comprehensive environmental sustainability model. The model was tested at 67 operating industrial manufacturing facilities in 12 countries over a period of 10 years. The results achieved included measured reductions of environmental impacts to air, land, and water from $5 \%$ to more than $95 \%$ of operational aspects compared to pre-model values. A significant catalyst for model success was identifying and applying innovative leadership and management principles that were required to modify business objectives and culture from purely capitalist incentives and objectives to sustainability-oriented goals. This was accomplished through a clear and understandable model, stated objectives, incentives, rewards and penalties, measuring results, data analysis, identifying and communicating areas where improvement was needed, model adaptations, transparent communication and feedback, and flexible timelines. The results indicate that the model can be scaled from the parcel to global level, assuming management and leadership principles are in place and properly supported.
\end{abstract}

Keywords: Sustainability model, contaminant risk, geologic vulnerability

\section{Introduction}

A sustainability model for any location in the world may seem impossible because of the sheer number of potential variables that greatly increase the complexity and because of the many differences between countries. However, this is just not the case. Sustainability is defined as creating and maintaining conditions under which humans can exist in productive harmony to support present and future generations (United Nations 2020 and United States Environmental Protection Agency [USEPA] 2020). The term "productive harmony" applies to the environment. Therefore, sustainability can be reduced to three variables that include (1) understanding the environment, (2) understanding how aspects of human activities impact the environment, and (3) developing and implementing measures to mitigate unacceptable risk (Rogers 2019a and 2019b).

Understanding the geological, hydrological, and ecological environment is the first step in building a sustainability model and is represented by the general term Geological Vulnerability. The second step is evaluating aspects of human activities that affect the environment either through negative or positive outcomes. The third variable is evaluating the effectiveness of risk reduction measures. An equation for sustainability is 
created by combining these three fundamental concepts through which a sustainability index is the output (see Equation 1 below). The Sustainability Index represents a measure of sustainability for any particular location with a higher value representing increased risk and harm to human health or the environment and therefore, less sustainable (Rogers 2020):

\section{Geologic Vulnerability X Operational Aspects $\mathrm{X}$ Risk Reduction Measures = Sustainability Index Equation 1}

The Sustainability Index can be scaled to evaluate environmental health of a single location or whole ecosystem depending on system inputs and evaluation criterion described in the following sections.

\section{Methods}

The methods to develop and examine geologic vulnerability, aspects of operations, and risk reduction measures will each be addressed separately and then will be combined into a sustainability model that is tested to evaluate its accuracy and effectiveness at reducing environmental risk caused by anthropogenic activities.

\subsection{Geologic Vulnerability}

Despite centuries of attempting to modify the places where we live and work, humans do not have complete control over the geologic and hydrogeologic environment. Therefore, an increased understanding of the geologic environment is required to minimize or eliminate the potential harmful effects of contaminants upon human health and the environment. To achieve this goal, an extensive understanding of the geology and hydrogeology is required. This must be followed up by a detailed understanding of the regional and local influence that the geology and hydrogeology play in the influence of contaminant fate and transport (Rogers 2019a).

The largest cities on Earth are dominated by a geologic environment of unconsolidated sedimentary deposits and are located near water. Most of those sedimentary deposits are saturated with water very near the surface, and function as a source of transportation since many of the water bodies are large enough to permit the transport of goods. More importantly for our survival, most of these water sources also provide potable water, including drinking water. However, the presence of water can also enhance the transport of contaminants because water acts as a solvent and can dissolve many pollutants and potentially transport them a long distance. This means that a chemical contaminant released from an anthropogenic source can potentially migrate undetected to a location where an exposure can occur and cause harm to humans and the environment. The basic scientific factors that control the severity of harm to the environment from pollutant releases are: (1) the environment and geology where the release occurred, (2) the amount of chemical release and over what period of time, and (3) the physical chemistry and toxicity of compounds released (Rogers 1996; Murray and Rogers 1999a; Kaufman et al. 2005, and Rogers 2018). 
To evaluate the environment and geology at the locations where a contaminate release has occurred requires a detailed understanding of the geology and hydrogeology in great detail so that an accurate assessment of contaminate fate and transport can be conducted. This type of assessment is commonly referred to as geologic vulnerability analysis. A logical first step in conducting geologic vulnerability analysis is to understand the near-surface geologic and hydrogeologic environmental on a local and regional scale. This information is commonly presented as a geologic map and a geologic vulnerability map. A geologic map provides detailed information of the subsurface with a perspective and concentration of effort toward providing information helpful to determine how contaminants may migrate in the subsurface environment so that a vulnerability map can be constructed. Geologic vulnerability analysis and mapping have been developed by Murray and Rogers (1999a and 1999b) and Kaufman et al. (2003 and 2005). Central to this method is a subjective numerical rating system using weighting coefficients for numerous geologic and hydrogeologic parameters (Rogers 1992; Rogers 1996; Murray and Rogers 1999a; Rogers 2002; Kaufman et al. 2005). These factors provide detailed subsurface information relevant to construct a geologic vulnerability map within any urban area and is presented as a matrix of vulnerability factors that are rated through a linear scoring scale as shown in Table 1 (Rogers 2016a, 2016b, and Rogers 2020).

\subsection{Aspects of Operations}

Aspects of operations are divided into two separate activities. The first is evaluating the potential risk posed by contaminants used or stored at any location and the second include aspects of human activities that may increase or decrease the potential for a release to the environment.

Table 1.

Geologic vulnerability matrix and scoring Scale.

\begin{tabular}{|c|c|c|}
\hline $\begin{array}{l}\text { Parameter } \\
\text { Identification }\end{array}$ & Parameter Description & $\begin{array}{l}\text { Rating } \\
\text { Strength }\end{array}$ \\
\hline \multirow[t]{4}{*}{1} & Depth to Groundwater & \\
\hline & Less than 10 feet below the ground surface & 10 \\
\hline & 10 to 30 feet & 5 \\
\hline & Greater than 30 feet & 1 \\
\hline \multirow[t]{4}{*}{2} & $\begin{array}{l}\text { Composition, extent, and thickness of soil units in the } \\
\text { vadose zone }\end{array}$ & 10 \\
\hline & Thick and extensive sequence of sand and gravel & 5 \\
\hline & Interbedded sands and clay deposits & 1 \\
\hline & Thick and extensive sequence of clay & \\
\hline \multirow[t]{4}{*}{3} & Composition, areal extent, and thickness of saturated zone & \\
\hline & Thick and extensive sequence of sand and gravel & 10 \\
\hline & Interbedded sands and clay deposits & 5 \\
\hline & Thick and extensive sequence of clay & 1 \\
\hline \multirow[t]{4}{*}{4} & Occurrence and relative abundance of groundwater & \\
\hline & $25 \%$ or less likelihood before encountering an aquiclude & 10 \\
\hline & $25 \%$ to $74 \%$ likelihood & 5 \\
\hline & Greater than $75 \%$ likelihood & 1 \\
\hline 5 & Area of groundwater recharge & \\
\hline
\end{tabular}




\begin{tabular}{|c|c|c|}
\hline & Significant area of recharge & 10 \\
\hline & Moderate area of recharge & 5 \\
\hline & Not a significant area of recharge & 1 \\
\hline \multirow[t]{4}{*}{6} & Areas of groundwater discharge & \\
\hline & Significant area of discharge & 10 \\
\hline & Moderate area of discharge & 5 \\
\hline & Not a significant area of discharge & 1 \\
\hline \multirow[t]{4}{*}{7} & Travel time and distance to point of potential exposure & \\
\hline & Less than 10 years & 10 \\
\hline & 10 to 25 years & 5 \\
\hline & Greater than 25 years & 1 \\
\hline \multirow[t]{4}{*}{8} & Source of potable water & \\
\hline & Current source of potable water & 10 \\
\hline & Potential source of potable water & 5 \\
\hline & Not a potential source of potable water & 1 \\
\hline
\end{tabular}

\subsection{Contaminant Risk Factors}

A required variable in understanding how a specific contaminant will behave in the environment originates from the physical chemistry of each individual chemical. The physical chemistry of a specific chemical can vary greatly and translates into a very different behavior when released into the environment. Therefore, the risk posed by each different chemical contaminant can vary by more than 8 orders of magnitude in some circumstances. With so much chemical variability, there is nearly an infinite number of outcomes and in many circumstances an extremely toxic contaminant may not present as much risk as a moderately toxic contaminant if it's released at the right location, in the right amount, and at the right time. This scenario commonly occurs if a more toxic chemical does not migrate and degrades quickly, and the less toxic chemical has higher mobility and persistence and lasts for decades before degrading. However, if an extremely toxic chemical were released in a heavily populated area, it can have the potential to inflict enormous harm as evidenced by the incident in Bhopal, India, where a chemical was released and inflicted casualties in the thousands in a short period of time (Rogers 2019b). An additional factor when evaluating chemical behavior in the environment is to consider how each contaminant behaves in air, water, and soil. The behavior of a chemical in the environment is influenced by factors that include solubility, vapor pressure, density, chemical stability, persistence, and adsorption potential (USEPA 1989; USEPA 1996; USGS 2006; Rogers et al. 2007a).

Toxicity is an important factor when examining risk but should not be the only factor when assessing the risk of a chemical released into the environment. Mobility and persistence are very often just as important if not more important because these two factors directly influence a chemical's ability to migrate in the geologic environment to a point of exposure. The environmental risk posed by specific contaminants to contaminant the air, the water, or the land, termed Contaminate Risk Factor (CRF) is a function of toxicity, mobility, and persistence (Kaufman et al. 2005; Rogers et al. 2007a). In general terms, the risk to humans or the environment only exists if a contaminate 
pathway is completed. In general terms, the CRF is expressed in Equation 2 (Kaufman et al. 2005; Rogers et al. 2007a).

$\mathrm{CRF}=$ Toxicity $\times$ mobility $\times$ persistence Equation 2

Toxicity values are continually updated by the United Stated Environmental Protection Agency (USEPA) Integrated Risk Information System (IRIS)(2019a). To guard against a false negative response, the toxicity value selected should reflect the highest toxicity value for any exposure pathway--ingestion, dermal adsorption, and inhalation regardless whether its carcinogenic or chronic. Mobility is calculated by multiplying Henry's Law constant and the retardation factor. Calculating mobility is presented as Equation 3 (Kaufman et al. 2005; Rogers et al. 2007a).

$\mathrm{M}=(\mathrm{H})(\mathrm{R})$ Equation 3

where: $\mathrm{M}=$ mobility

$\mathrm{H}=$ Henry's Law constant

$\mathrm{R}=$ retardation factor

Henry's Law constant $(\mathrm{H})\left(\mathrm{atm} . \mathrm{mol}^{-1} \mathrm{~m}^{-3}\right)$ is very useful in evaluating the mobility of a specific chemical since it's a measure of the tendency of a chemical to evaporate in the atmosphere and also is used to evaluate water solubility. is a measure of the tendency for substances to volatilize (Sander 1999). Henry's law is related to vapor pressure and is expressed as Equation 4 (Kaufman et al. 2005; Rogers et al. 2007a).

$\mathrm{H}=(\mathrm{VP})(\mathrm{MW})\left(\mathrm{W}_{\mathrm{s}}\right) \quad$ Equation 4

where: $\mathrm{VP}=$ vapor pressure

$$
\begin{aligned}
& \mathrm{MW}=\text { molecular weight } \\
& \mathrm{W}_{\mathrm{s}}=\text { water solubility }
\end{aligned}
$$

The retardation factor is presented as Equation 5.

$$
\mathrm{R}=1+\frac{(\mathrm{\rho b})(\mathrm{Kd})}{\eta} \text { Equation } \mathbf{5}
$$

where: $\mathrm{R}=$ retardation factor

$$
\begin{aligned}
& \mathrm{Qb}=\text { bulk density of aquifer matrix }\left(\mathrm{g} / \mathrm{cm}^{3}\right) \\
& \mathrm{Kd}=\text { distribution coefficient }\left(\mathrm{mL} \bullet \mathrm{g}^{-1}\right) \\
& \eta=\text { effective porosity (calculated as a percent value) }
\end{aligned}
$$

The distribution coefficient is presented as Equation 6.

$$
\mathrm{Kd}=(\mathrm{Foc})(\mathrm{Koc}) \text { Equation } 6
$$

where: $\mathrm{Kd}=$ distribution coefficient

Foc $=$ organic carbon partition coefficient $(\mathrm{kg} / \mathrm{kg})$

$\mathrm{Koc}=$ fraction of total organic carbon in soil $(1 / \mathrm{kg})$

Values for the fraction of organic carbon should be collected in the field. If field collection is not possible, standard values and ranges can be obtained from USEPA (1996), Wiedemeier (1999), USEPA (2002a and 2002b), and Suthersan and Payne (2005). The retardation factor represents the ratio between groundwater and contaminate migration in groundwater or other media. Therefore, if the value calculated equals 1 , this implies that both are traveling at the approximate same rate (USEPA 1989, 2002b). 
The CRF for water is calculated in Equation 7 by multiplying the inverse of the chemical compound's Toxicity ( $\mathrm{T}$ ), by the inverse of its Mobility $(\mathrm{M})$ and its Persistence $(\mathrm{P})$.

$\mathrm{CRF}_{\text {WATER }}=\underline{1} \times \underline{1} \times(\mathrm{P}) \quad$ Equation 7

(T) (M)

where: $\mathrm{CRF}_{\mathrm{GW}}=$ Contaminant Risk Factor for Groundwater, and:

$$
\begin{aligned}
& \mathrm{T}=\text { Toxicity } \\
& \mathrm{M}=\text { Mobility } \\
& \mathrm{P}=\text { Persistence }
\end{aligned}
$$

The inverse of the toxicity value must be used because the integer values assigned for toxicity decrease with increasing carcinogenicity (USEPA 2019a). The inverse of the mobility values must also be used because the calculated values of retardation decrease with increasing mobility.

The CRF for soil is calculated in Equation 8 by multiplying the inverse of the chemical compound's Toxicity (T), by its Mobility and its persistence.

\section{$\mathrm{CRF}_{\text {soil }}=1 \times(\mathrm{M}) \times(\mathrm{P}) \quad$ Equation 8}

Atmospheric contaminants are released to the atmosphere as a gas and as particulate matter, and sometimes as a water droplet (USEPA 2018).

The $\mathrm{CRF}_{\text {AIR }}$ is expressed as Equation 9. (Kaufman et al. 2011; Rogers et al. 2012, Rogers 2018).

$\mathrm{CRF}_{\mathrm{AIR}}=$ Toxicity $\times\left[\right.$ (Mobilitygas $_{\mathrm{g}} \times$ Persistence $\left._{\mathrm{gas}}\right)+$ (Mobility $_{\text {particulate }} \times$ Persistence $\left._{\text {particulate }}\right)$ Equation 9

Mobility for air is represented separately for contaminants in the gas phase and for solid particulate matter, and is combined with persistence. The mobility of atmospheric contaminants in the gas phase is presented as Equation 10.

$\mathrm{M}=(\mathrm{H})$ Equation 10

where: $\mathrm{M}=$ mobility

$$
\mathrm{H}=\text { Henry's Law constant }
$$

The mobility of a contaminant sorbed to particulate matter is represented by Equation 11.

$$
\mathrm{M}_{\text {(particulate) }}=\frac{1}{\mathrm{SpG}} \times \mathrm{Koc} \quad \text { Equation } 11
$$

where: $\mathrm{M}_{\text {(particulate) }}=$ mobility of a contaminant sorbed to particulate matter

Spg $=$ Specific gravity

Koc $=$ partitioning coefficient

The CRF for air is presented as Equation 12.

$\mathrm{CRF}_{\text {AIR }}=\underline{1} \times\left[\left(\mathrm{M}_{\text {gas }} \times \mathrm{P}_{\text {gas }}\right)+\left(\mathrm{M}_{\text {particulate }} \times \mathrm{P}_{\text {particulate }}\right)\right] \quad$ Equation 12 
where: $\mathrm{CRF}_{\mathrm{AIR}}=$ Soil Contaminant Risk Factor

$\mathrm{T}=$ Toxicity

$\mathrm{M}_{\mathrm{gas}}=$ Mobility of a contaminant in the gas phase

$\mathrm{P}_{\text {gas }}=$ Persistence of a contaminant in the gas phase

$\mathrm{M}_{\text {particulate }}=$ Mobility of a contaminant sorbed to particulate matter

$\mathrm{P}_{\text {particulate }}=$ Persistence of a contaminant sorbed to particulate matter

CRF analysis provides valuable information for assessing and predicting contaminate behavior anywhere in the environment as demonstrate by examining Table 2, which lists CRFs for many common contaminants of the world. Analysis of the values listed in Table 2 demonstrate the variability of risks posed by contaminants released in different media. For instance, the variability of PCBs in the environment ranges by more than 7 orders of magnitude.

Table 2.

Contaminant Risk Factors for Water, Soil, and Air for each Contaminant Group.

\begin{tabular}{|c|c|c|c|}
\hline $\begin{array}{l}\text { Contaminant } \\
\text { Type }\end{array}$ & $\begin{array}{l}\text { Groundwater CRF } \\
\text { (CRF }_{\text {WATER })}\end{array}$ & $\begin{array}{l}\text { Soil CRF } \\
\left(\text { CRF }_{\text {SOIL }}\right)\end{array}$ & $\begin{array}{l}\text { Air CRF } \\
\left(\mathrm{CRF}_{\text {AIR }}\right)\end{array}$ \\
\hline DNAPL & 978.00 & $1,508.00$ & 67.52 \\
\hline LNAPL & 0.47 & 10.16 & 20.23 \\
\hline PAH & 0.001 & 142.00 & 124.82 \\
\hline Total PCBs & 0.0004 & $5,264.00$ & 37.00 \\
\hline Chlordane & 0.0001 & $7,501.00$ & 173.00 \\
\hline Arsenic & 27.24 & $3,723.00$ & 44.00 \\
\hline Chromium VI & $1,926.00$ & 5.17 & 210.00 \\
\hline Lead & 0.55 & 52.44 & 3.45 \\
\hline Mercury & 2.56 & $22,013.00$ & 166.00 \\
\hline
\end{tabular}

DNAPL $=$ Volatile organic compounds heavier that water

LNAPL $=$ Volatile organic compounds lighter than water

$\mathrm{PAH}=$ Polynuclear aromatic hydrocarbons

PCBs = polychlorinated biphenyls

\subsection{Operational Aspects}

Facility risks can be characterized with two measured variables that include Aspect Risks of Operations and Risk Reduction Actions. Much of this information can be obtained from data contained in an environmental audit. The recommended point values for each attribute is presented within a scaled range. Higher point values indicate higher relative risk. Categories included in the checklist follow the environmental audit guidelines and are (Rogers 2018 and Rogers 2019a and 2019b):

- $\quad$ Air (zero to 7 points)

- $\quad$ Solid and Hazardous Waste and Landfills (zero to 7 points)

- Water (zero to 7 points)

- $\quad$ Spills (zero to 5 points)

- $\quad$ PCBs (zero to 5 points)

- Toxic Substance Control Act or Equivalent (Contaminant Risk Factors) (zero to 5 points) 
- $\quad$ Community Right to Know or Equivalent (zero to 5 points)

- Tanks (zero to 3 points each)

- $\quad$ Asbestos (zero to 3 points)

- $\quad$ Regulatory Inspections (zero to 5 points each)

- $\quad$ Site Inspection (zero to 3 points on each item noted)

USEPA defines conducting an environmental audit as a systematic evaluation to determine the conformance to quantitative specification to environmental laws, regulations, standards, permits, or other legally required documents (USEPA 2018). This definition is consistent with environmental audits in most countries of the world including China, the EU, and others. Conducting an environmental audit is the first step on a long and winding road toward environmental compliance and ultimately can lead to the path of sustainability and environmental stewardship. Most large companies with several manufacturing locations conduct environmental audits on a regular basis. Some choose to conduct environmental audits more often than others, but most seem to choose conducting an environmental audit every year or every two years. Some companies conduct environmental audits with in-house staff to retain institutional knowledge. Some choose to retain an environmental consulting firm to conduct environmental audits because it's conducted by an independent third party. Some environmental audits are conducted without any prior notice and some are conducted with prior notice.

Typically an audit is conducted by an environmental professional and much of the information from an environmental can be used to evaluate the environmental risks posed at any facility or property. The objectives of an environmental audit include (1) verifying compliance with environmental requirements, (2) evaluating the effectiveness of in-place environmental management systems, and (3) assessing risks posed from regulated and unregulated materials, chemicals, and practices. From a fundamental point of view, the typical environmental audit encompasses evaluating subject areas that include evaluating how operations at a facility impact the environment through the land, water, and air.

If the environmental audit is announced prior the audit date, a request for applicable documents to be available to be reviewed in advance audit will save time. As applicable to the facility being reviewed, the following list of documents should be available for review during the site visit.

1.

2.

Current site map

3. Current process flow diagrams depicting: inputs, process units, waste streams, and other outputs

4. List of processes that have been shut down since the last audit

5. List of processes that are expected to start up with the next 12 to 24

months

6. SPCC Plan

7. Spill reports for the last three years

8. All RCRA manifests since the last audit 
9.

audit

10. waste

11.

12.

13.

14.

15.

16.

All special waste notifications and shipping documents since the last All analytical tests results and determination for special and hazardous All analytical tests for each non-hazardous waste stream Contingency plan

Personnel training records since the last audit

List of arrangements with local agencies

NPDES permit and most recent application

of permit limit exceedances since the last audit

17. Stormwater plan, intent to comply documents, and all monitoring reports and sample data

18.

All notices of violation, noncompliance letters, or consent orders including facility's noncompliance explanations and, if in significant noncompliance, the facility's plan to return to compliance

19.

Water flow diagrams and water balances

20.

Sketches of all wastewater treatment systems within the facility

21.

Names of wastewater analytical laboratory, a list of all analytical methods used for wastewater analysis, and the quality assurance/quality control procedures used for wastewater sample collection and analysis

22.

23.

24. or contractors for the past three years

25.

26. or water)

27.

28.
Air permit application modifications

All construction and operating permits for air sources

Copies of all visible emission observations taken by facility personnel Environmental management plan

Any other environmental permit to operate (associated with air, land,

Waste shipment summary for the past two years

Toxic Release Inventory Reports (Form R) for the past two years

For facilities not in the United States, and as applicable to the specific country, province or state, additional documents to be made available to the reviewers include:

1. Noise studies and noise compliance (e.g., Mexico, China etc.)

2. Environmental Impact Assessment (EIA)

3. Operating Permits

4. European Union Registration, Evaluation, Authorization, and Restriction of Chemicals (REACH) certification status for those locations within the European Union.

As demonstrated by the list above, an environmental audit, if conducted correctly, should provide enough technical information to conduct an environmental risk evaluation.

\section{Discussion}


Three distinct elements have now been developed that can be combined into a model for sustainability that include the following:

1. Understanding the Natural Environment

2. A detailed analysis of the aspects of operations

3. Evaluating the effectiveness or ineffectiveness of risk reduction actions

Combining these three elements we arrive at an equation with an output that is termed the Sustainability Index and is presented as Equation 13 (Rogers 2018 and Rogers 2020). Note that productive actions to reduce risk lower the overall Sustainability index by using the inverse.

\section{Geologic Vulnerability X Operational Aspects X Risk Reduction Measures = Sustainability Index Equation 13}

Examining the method for calculating the Sustainability Index, a higher Sustainability Index value indicates higher risk. The Contaminant Risk Factor is a critical value and appears in many places within the Operational Aspects variable. The CRF appears at several locations that include air, water, solid and hazardous waste, EPCRA, TSCA, and pollution prevention efforts. Critical in this evaluation are chemicals and their behavior when released into the environment that includes each chemical's toxicity, persistence, and mobility. Each of these factors are important especially when combined with geologic vulnerability because it can be used as a predictor to evaluate whether a release of any particular chemical will cause harm and at what scale. Contaminant Risk Factors are also part of the evaluation for the Risk Reduction Measures. Since CRFs are part of two of the three elements of the Sustainability Model (Operational Aspects and Risk Reduction Measures) it ensures that the Sustainability Index that is calculated results in a higher risk if chemicals are used at a specific facility that have high CRF's. On the inverse, eliminating chemicals with high CRF's will have a significant positive effect at lowering risks and greatly reducing the Sustainability Index.

\section{Sustainability Model Application}

To evaluate whether the Sustainability Index can actually be effective at lowering environmental risk, increasing sustainability, and achieving environmental stewardship, it must implemented at operating manufacturing facilities and put through rigorous testing. For a period of 10 years that included 5 two-year evaluation periods, as many as 67 manufacturing facilities in 12 countries were tracked using the Sustainability Model presented in the previous section. Some facilities were not evaluated during all five periods because of mergers, acquisitions, divestitures, new construction, or were shut down.

An environmental audit was used to gather the necessary information to score each facility's Operational Aspects and Risk Reduction Measures and were conducted at least every 2 years. Figure 1 and 2 show a graphical representation of Aspects of Operations and Risk Reduction Measures for each facility during each of the 2 year evaluation 
periods for 2009 and 2010 and then from 2018 and 2019, respectively. Upon examination of Figure 1 and 2, the Aspects of Operations did not vary and only decreased slightly during the 10-year evaluation period. However, increased performance and attention to Risk Reduction Measures were significant. The main reason that Operational Aspects did not appear to improve significantly is because many facility's Operational Aspect improvements were offset by expanding operations which tended to increase complexity of operations. Another measure of Risk Reduction Measures is to compare the number of regulatory inspections with the number of Notice of Violations (NOVs) issued by regulatory authorities. The number of inspections remained relatively constant but the number of NOVs decreased by approximately $75 \%$. This positive outcome is due to a significant increase in Risk Reduction Measures that also reduced Operational Aspects.

The Risk Reduction Action also represent initial efforts to create and improve sustainability initiatives. Some manufacturing locations have achieved nearly a zero waste-generating status of solid or hazardous waste and have also achieved decreases in water use by more than $95 \%$.

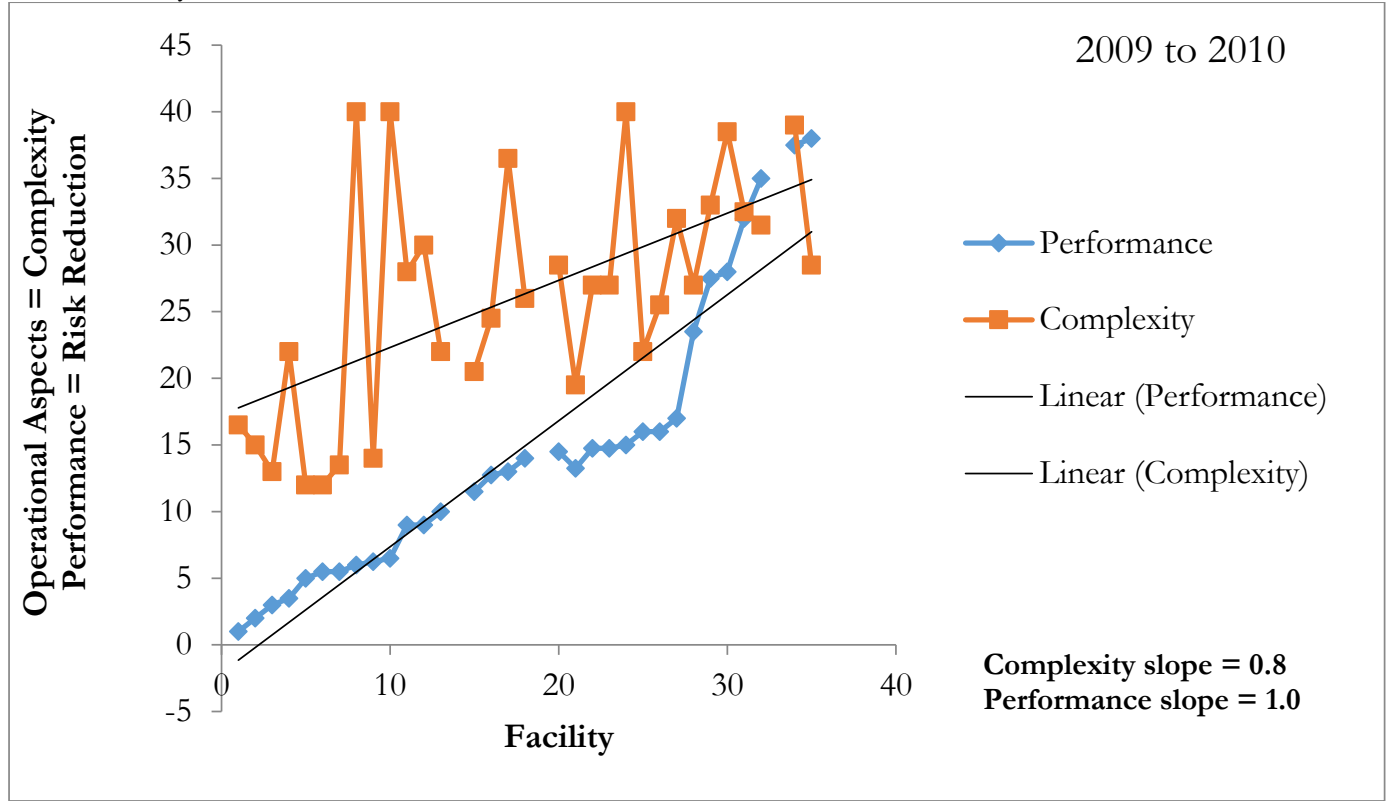

Figure 1.

First 2 year evaluation period. 


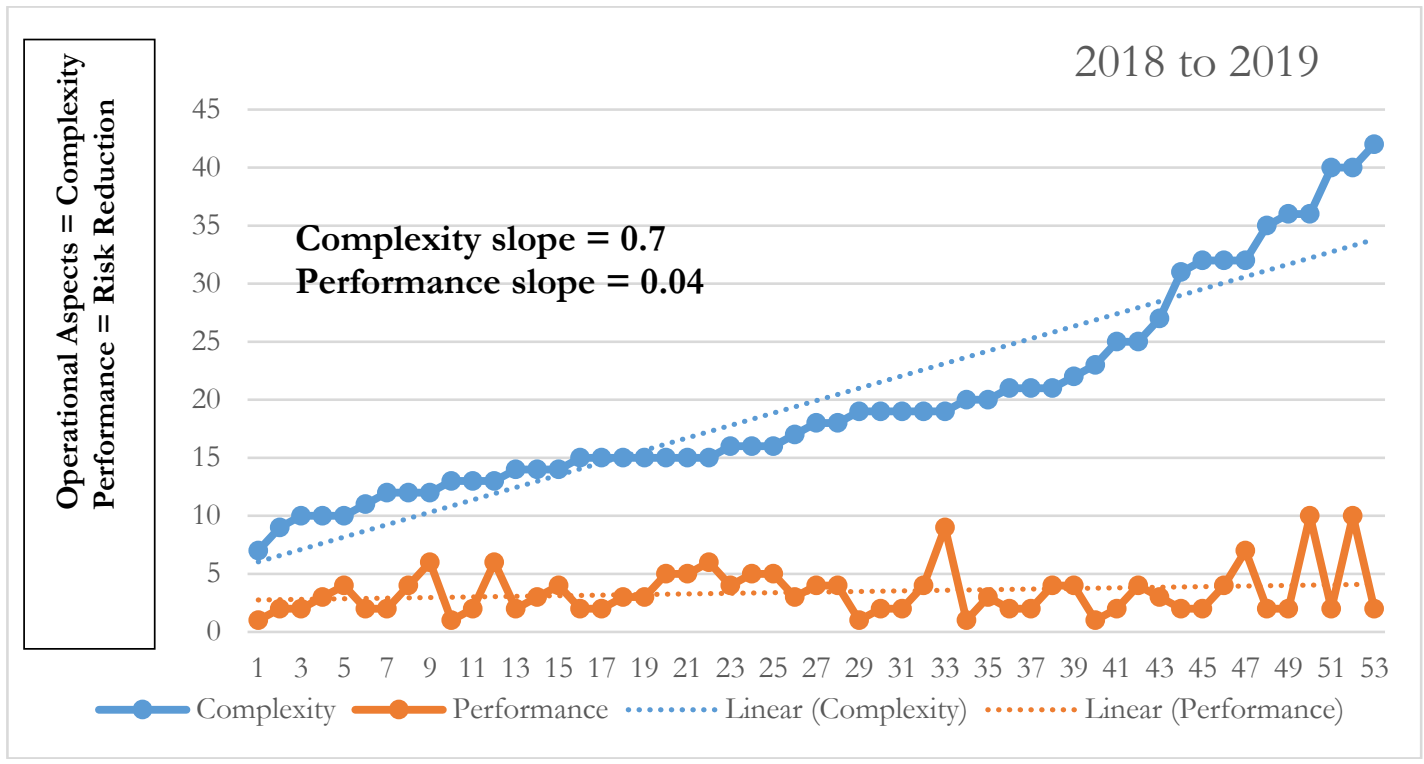

Figure 2.

Last 2 year evaluation period.

\section{Summary and Conclusions}

The Sustainability Model has undergone 10 years of testing at as many at 67 manufacturing locations in 12 different countries of the world. Over the 10 year period, improvements in Risk Reduction Measures have been realized by an average of $80 \%$ resulting in a significant reduction in environmental non-compliance and releases of hazardous substances to the environment and greatly improve the sustainability of each facility (Rogers 2019a and 2019b). Efforts to reduce Operational Aspects were largely offset by new or more strict environmental regulations, facility expansion, new equipment, or increased production that required additional permitting and regulatory limitations. However, even with the offsets, slightly more than $50 \%$ of facilities reduced Operational Aspects.

The most significant challenge during the 10-year implementation and evaluation period was changing cultural attitudes and behaviors. This highlights the difficult actions that must be taken are changing our cultural attitudes and behaviors toward Earth (Rogers 2019b).

The success of implementing a sustainability program could not have occurred without acknowledging and overcoming cultural attitudes and behaviors ingrained in most western capitalist organizations which is a constant drive for growth and profit first and everything else second. The issues and challenges surrounding and weaved within the solutions for overcoming pollution will take commitment and sacrifice from each of us. One person may not make much of a difference but collectively we can and must 
(Rogers 2019b). Changing attitude and culture requires several steps and involves all organization levels. Those steps include (Rogers 2019b):

1. A corporate culture of respect and commitment to establishing and maintaining environmental stewardship for the Earth

2. Education and training

3. A clear plan with stated purpose and goals

4. Incentives, rewards and penalties

5. Measuring and recording performance

6. Data analysis

7. Plan adaptations including additions or subtractions and adjusting timelines

\section{References}

Kaufman, M. M., Rogers, D. T., and Murray, K. S. 2003. Surface and Subsurface Geologic Risk Factors to Ground Water Affecting Brownfield Redevelopment Potential. Journal of Environmental Quality. Vol. 32. pp.490 - 499 .

Kaufman, M. M., Rogers, D. T., and Murray, K. S. 2005. An Empirical Model for Estimating Remediation Costs at Contaminated Sites. Journal of Water, Air and Soil Pollution. Vol. 167. pp. 365-386.

Kaufman, M. M., Rogers, D. T. and Murray, K. S. 2011. Urban Watersheds: Geology, Contamination, and Sustainable Development. CRC Press. Boca Raton, FL. 583 p.

McKone, T. E. and Enoch, K. G. 2002. CalTox ${ }^{\mathrm{TM}}$, A Multimedia Total Exposure Model Spreadsheet Users Guide. Lawrence Berkeley National Laboratory. LBNL 47399. University of California, Berkeley, CA.

Michigan Department of Environmental Quality. 2019. Chemical Update Worksheets. Remediation and Redevelopment Division. Lansing, Michigan.

Murray, K. S. and Rogers, D. T. 1999a. Groundwater Vulnerability, Brownfield Redevelopment and Land Use Planning. Journal of Environmental Planning and Management. Vol. 42. no. 6. pp. 801-810.Rogers, D. T. 1996. Environmental Geology of Metropolitan Detroit. Clayton Environmental Consultants, Novi, MI.

Murray, K. S. and Rogers, D. T. 1999b. Evaluation of Groundwater Vulnerability in an Urban Watershed. Proceedings of the $2^{\text {nd }}$ International Congress on Water Resources and Environmental Research. Brisbane, Australia. pp. 877-883.

Payne, F. C., Quinnan, J. A. and Potter, S. T. 2008. Remediation Hydraulics. CRC Press. Boca Raton, FL.

Rogers, D. T. 1996. Environmental Geology of Metropolitan Detroit. Clayton Environmental Consultants, Novi, MI.

Rogers, D. T. 2002. The Development and Significance of a Geologic Sensitivity Map of the Rouge River Watershed in Southeastern Michigan, USA. In; Bobrowsky, P. T. editor. Geoenvironmental Mapping: Methods, Theory, and Practice. A. A. Balkema Publishers. The Netherlands. pp.295 319.

Rogers, D. T., Murray, K. S. and Kaufman, M. M. 2007. Assessment of Groundwater Contaminant Vulnerability in an Urban Watershed in Southeast Michigan, USA. . In: Howard, K. W. F. editor. Urban Groundwater - Meeting the Challenge. Taylor \& Francis, London, England.

Rogers, D. T., Murray, K. S. and Kaufman, M. M. 2012. Environmental Risk Analysis through Integration of Geologic Vulnerability and Air, Water, and Soil Contaminant Risk Factor Derivation. International Geological Congress. Vol. p. 3003. Brisbane, Australia.

Rogers, D. T. 2016a. Next Generation of Urban Hydrogeologic Investigations. Journal of the Italian Geological Society. Rome, Italy. Vol. 39. No 1. P. 349-353.

Rogers, D. T. 2016b. Scientific Advancements that Improve the Conceptual Site Model in Urban Hydrogeological Site Investigations. 35th International Geological Congress. Paper 3019. Cape Town South Africa.

Rogers, D. T. 2018. Derivation of a Comprehensive Environmental Risk Model for Urban Groundwater Protection. International Association of Hydrogeologists Congress. Vol. 1. Daejeon, Korea. 
Rogers, D. T. 2019a. Key Policy Changes Required to Reduce Environmental Degradation in the United States and Beyond. International Association of Hydrogeologists $46^{\text {th }}$ Congress. Vol. 1. p.328. Malaga, Spain.

Rogers, D. T. 2019b. Environmental Compliance and Sustainability: Global Challenges and Perspectives. CRC Press, Boca Raton, FL. 543p.

Rogers, D. T. 2020. Urban Watersheds: Geology, Contamination, Environmental Regulations, and Sustainability. CRC Press, Boca Raton, FL. 615p.

Sander, R. (1999). Henry's Law Constants for Inorganic and Organic Species of Potential Importance in Environmental Chemistry (Version 3). http://www.henrys-law.org. (accessed May 20, 2018).

Sharkey, T.D, A.E. Wiberley, A.R. Donohue. 2008. Isoprene Emission from Plants: Why and How Annals of Botany. Vol. 101: 5-18.

Suthersan, S. S. and Payne, F. C. 2005. In Situ Remediation Engineering. CRC Press. Boca Raton, FL.

United Nations. 2020. What is Sustainable Development. https://www.un.org/sustainabledevelopment. (accessed April 15, 2020).

United States Environmental Protection Agency (USEPA). 1989. Transport and Fate of Contaminants in the Subsurface. USEPA. EPA/625/4-89/019. Washington, D. C.

United States Environmental Protection Agency (USEPA). 1996. Bioscreen. Natural Attenuation Decision Support System, Version 1.4. USEPA. Office of Research and Development. Washington, D. C.

United States Environmental Protection Agency (USEPA). 2002a. Supplemental Guidance for Developing Soil Screening Levels for Superfund Sites. USEPA. Office of Solid Waste and Emergency Response. OSWER 9355.4-24. Washington, D. C.

United States Environmental Protection Agency (USEPA). 2002b Health assessment of 1,3-butadiene.

National Center for Environmental Assessment, USEPA/600/P-98/001F. Washington, D.C.

United States Environmental Protection Agency (USEPA) 2018. National Air Quality: Status and Trends

of Key Air Pollutants. https://www.epa.gov/air-trends. (accessed April 20, 2019.)

United States Environmental Protection Agency (USEPA). 2019a. Integrate Risk Information System (IRIS). http://www.epa.gov/ncea/iris/intro.htm. (accessed March 31, 2019).

United States Environmental Protection Agency (USEPA) 2019b. EPA Online Tools for Site Assessment Calculation. Ecosystems Research Division. USEPA. http://www.epa.gov/athens/learn2model/part-two/onsite/retard.html. (accessed March 31, 2019).

United States Environmental Protection Agency (USEPA). 2020. What is Sustainability? https://www.epa.gov/sustainability. (accessed April 15, 2020).

United States Geological Survey (USGS) 2006. Volatile Organic Compounds in Nation's Ground Water and Drinking-Water Supply Wells. USGS Circular 1292. Washington, D. C.

Wiedemeier, T. H. Rifai, H. S. Newell, C. J. and Wilson, T. J. 1999. Natural Attenuation of Fuels and Chlorinated Solvents in the Subsurface. John Wiley \& Sons. New York, NY. 